\title{
Os ESTADOS UNIDOS ESTÃO SE ENCAMINHANDO PARA UMA DITADURA?*
}

ERIC POSNER ${ }^{\dagger}$

Presidentes possuem mais poder atualmente, mas há boas razões históricas para essa tendência.

A democracia americana está condenada? Uma tradição intelectual voltada para a fundação do país defende que sim. Os opositores da Constituição argumentaram que ela criaria uma ditadura nacional. Estes oponentes perderam a batalha no momento da fundação (founding era) do país, mas o tema seria levado adiante por críticas aos presidentes George Washington, Abraham Lincoln, Franklin Delano Roosevelt, Ronald Reagan, e praticamente a todos os outros presidentes, grandes ou pequenos. Até agora, os pessimistas provaram-se errados.

No entanto, sentimentos de "fim dos tempos" são difíceis de abalar. Hoje, críticos como Matthew Yglesias apontam para a polarização do eleitorado, a paralisia do Congresso, e, acima de tudo, uma série de ações presidenciais que, argumentam eles, estão expandindo o poder presidencial além dos limites constitucionais. O Professor de Yale Bruce Ackerman acredita que, mais cedo ou mais tarde, um extremista carismático tomará posse do Salão Oval e, sem interferência de freios e contrapesos, implementará um programa fanático que comprometerá as liberdades dos americanos.

É impossível provar que estes pessimistas estão errados -- todos os impérios caíram e os Estados Unidos certamente cairão, eventualmente.

${ }^{*}$ Texto original publicado pela revista Slate, em 23 de outubro de 2015:

$<$ http://www.slate.com/articles/news and politics/view from chicago/2015/10/americ an presidential power is not leading to dictatorship.html >. Tradução e revisão de Antonio Sepulveda, Professor da Universidade Federal Fluminense (UFF), Rio de Janeiro, Brasil, Doutorando em Direito pela Universidade Estadual do Rio de Janeiro (UERJ), Rio de Janeiro, Brasil, e Pesquisador pelo Laboratório de Estudos Teóricos e Analíticos sobre o Comportamento Institucional (LETACI/UFRJ), e Igor de Lazari, Mestrando em Direito pela Universidade Federal do Rio de Janeiro (UFRJ), Rio de Janeiro, Brasil, e Pesquisador pelo Laboratório de Estudos Teóricos e Analíticos sobre o Comportamento Institucional (LETACI/UFRJ). A tradução foi realizada de acordo com autorização autoral, formalizada em 27 de outubro de 2015.

${ }^{\dagger}$ Professor da Escola de Direito da Universidade de Chicago, autor do livro The Twilight of International Human Rights Law. 
Os críticos também possuem o cuidado de não prever o colapso tão cedo; eles estão falando de uma data futura indefinida, provavelmente quando eles não estiverem mais por perto para serem avisados de que suas previsões não vieram a acontecer. Mas seus diagnósticos estão todos errados. O acréscimo de autoridade no poder executivo não é uma violação das tradições constitucionais, mas uma ferramenta. A expansão do poder executivo não tem minado as liberdades americanas; preservouas contra as ameaças nacionais e estrangeiros. O projeto constitucional do século 18 teve de adaptar-se às condições modernas, e fê-lo razoavelmente bem.

A primeira coisa a entender é quão modestas as acusações são. $\mathrm{O}$ presidente Barack Obama ainda é acusado de violar prazos do Affordable Care Act e da Lei Dodd-Frank; de regular as emissões de gases de efeito estufa sob o Clean Air Act, um estatuto de 1970 que nunca se imaginou regular o dióxido de carbono como um poluente; de usar força militar na Líbia e contra ISIS sem autorização do Congresso Nacional; de se recusar a deportar imigrantes não autorizados; de nomear funcionários do governo sem a confirmação do Senado enquanto o Congresso estava em recesso; e de flexibilizar a lei No Child Left Behind, conquista legislativa de George W. Bush,

Mas nada disso é a marca de um ditador. O Congresso aprova leis profundamente complexas que delegam poderes para o presidente para criar centenas de regras e para executá-las. Os prazos são impróprios; ninguém pode prever quanto tempo vai demorar para implementar programas que afetam milhões de pessoas. Apressar a realização de um programa para concluí-lo antes do prazo raramente é sábio. O Congresso aprova estas leis com a presunção de que o presidente vai usar os poderes administrativos que lhe são conferidos para tratar de problemas imprevistos; uma vez que gases de efeito estufa emergiram como uma ameaça ao bem-estar humano, a lei autorizou o presidente a agir.

Presidentes têm usado forças militares em operações sem a autorização do Congresso Nacional quase desde a fundação do país. A razão para isso é que as novas ameaças muitas vezes surgem antes mesmo que o Congresso possa agir. A decisão de Obama de não deportar imigrantes indocumentados era apenas uma continuação da política do presidente George W. Bush e de outros antecessores; tudo o que era novo era o seu reconhecimento público de que é isso que ele estava fazendo. Nomeações durante o recesso do Congresso também são uma tradição que remonta à fundação do país. Originalmente criada para manter o governo funcionando quando o Senado estava em recesso, hoje elas também são usadas quando o Senado está num beco sem saída. E a lei No Child Left Behind autoriza o presidente a flexibilizar suas exigências, conforme muitos outros estatutos aprovados pelo Congresso. 
Bush também foi acusado de ser um ditador pelos democratas que agora defendem Obama. Bush não usou força militar sem a autorização do Congresso, mas ele usou seus poderes de comandante-em-chefe agressivamente - alegando que ele poderia realizar investigações, interrogatórios coercivos, e deter terroristas estrangeiros sem julgamento. A maioria destas atividades estavam em conflito com a leis aplicáveis. Mas Bush argumentou que estas leis interferiam na sua capacidade de prosseguir com a guerra contra a Al-Qaida, então ele precisou ceder a esse imperativo. Ele também sustentou, no início do conflito com a AlQaida, que requerer autoridade adicional ao Congresso seria imprudente porque a publicidade do ato poderia alertar os terroristas. Mas quando vazamentos de informações tornavam insubsistentes estas preocupações, ele pediu e obteve autorização legal para a maioria do que já estava fazendo e restringiu suas táticas mais agressivas.

Novamente, Bush estava fazendo muito daquilo que outros presidentes já tinham feito. Os críticos liberais concentraram-se em teorias agressivas de poder presidencial, desenvolvidas por alguns dos advogados de sua administração, que argumentavam que Bush poderia desafiar leis que interferiam na sua autoridade de comandante-em-chefe. Este argumento parecia implicar que Bush poderia fazer o que quisesse, desde que se relacionasse a segurança nacional, na sua opinião. Talvez sim, mas Bush não usou essa teoria para aprisionar seus adversários ou censurar a imprensa, para implementar extremas e impopulares escolhas políticas, como um ditador normal faria. Bush não realizou praticamente nada no âmbito interno.

De fato, os advogados do governo Bush provavelmente estavam certos. A fim de dar a Obama a máximo de flexibilidade, seus advogados têm interpretado a linguagem jurídica com flexibilidade considerável por exemplo, definindo a palavra "hostilidades" de modo a não abranger uma campanha de bombardeio a fim de escapar dos limites legais sobre a guerra na Líbia -- sem explicar por que o sentido comum de palavras é substituído por significações mais restritas quando aplicadas ao presidente. A única resposta é que a posição constitucional especial do presidente lhe confere o direito a algum grau de deferência dos outros ramos do governo.

Ocorreu uma pequena, porém relevante "tempestade em copo d'água" quando, em 2006, o governo Bush foi acusado de fomentar uma "crise constitucional" por meio de razões de sanção de leis (issuing statements) que as interpretavam restritamente. Na verdade, os presidentes lavraram tais razões ao longo de décadas. As declarações não possuem status de lei -- não possuem força executória judicial, por 
exemplo. Eles simplesmente indicam como o Executivo planeja implementar as leis, refletindo interpretações jurídicas que o Executivo deve realizar a fim de ajustá-las às circunstâncias. Até onde sei, ninguém jamais mostrou que as declarações de Bush privaram alguém de seus direitos legais, e Obama deu continuidade a esta prática.

Indo mais ao ponto, quando se tenta identificar as acões mais importantes e controversas de Bush e Obama, todas elas envolvem o consentimento do Congresso. Para Bush, o Congresso autorizou as invasões do Afeganistão e do Iraque, a expansão das autoridades de vigilância e de detencão, um grande corte de impostos. No Child Left Behind, e US\$ 700 bilhões para socorrer o sistema financeiro em 2008. Para Obama, o Congresso autorizou um plano de estímulo de US\$ 787 bilhões. o Affordable Care Act, e uma profunda reforma da regulacão financeira. Acões unilaterais dos presidentes foram incrementais ou intersticiais -por vezes, à frente de autorizacão do Congresso Nacional, modificando as leis à luz das alteracões das circunstâncias e imperativos burocráticos, com base em autoridades existentes.

Então, por que a preocupacão? Poderes presidenciais têm aumentado, sem dúvida, ao longo dos séculos, mas a razão é apenas que o governo efetivo hoie exige uma presidência forte. A pequena sociedade agrária do final do século 18 poderia ser governada principalmente pelos Estados; o pequeno governo federal empregou algumas milhares de pessoas, e lidava com coisas como servicos postais, questões alfandegárias e defesa contra os nativos americanos. No século 19, estradas de ferro, telégrafos e telefones associados a um mercado nacional, requerendo, em última análise, a intervencão e regulacão do governo federal além dos limites dos Estados. Este processo se acelerou no século 20, resultando em uma maior transferência de poder dos Estados para o governo nacional e do Congresso para o presidente, a quem se atribui um aparato burocrático para resolver os problemas intermináveis causados pela industrialização, o avanço da tecnologia, e a emergência de ameaças externas.

Com grande poder para fazer o bem vem o poder para abusar. Os fundadores se preocuparam com a criacão de Césares e Cromwells; hoie, Hitler é o demônio de todos. E é verdade que Nixon e alguns de seus antecessores espionaram seus adversários políticos e usaram outros truques que não podem ser defendidos. Mas o sistema político dos EUA não produziu quaisquer ditadores, nunca; em alguma medida, a nossa própria experiência precisa superar medos com base em eventos de países estrangeiros e do passado distante.

A estagnação econômica, ameaças externas e degradação ambiental criaram momentos de ansiedade, e em tempos de ansiedade as pessoas olham para o governo. A verdadeira fonte de ansiedade não é o engrandecimento presidencial -- essa é a solução. A verdadeira fonte de 
ansiedade é a incapacidade de um presidente, mesmo muito poderoso, de resolver qualquer um desses problemas. Mas já que é mais fácil culpar alguém do que reconhecer que alguns problemas são insolúveis, a ansiedade sobre o estado do mundo foi transmutada em ansiedade sobre a estrutura institucional do governo. Isso pode ser a razão por que as pessoas reclamam sobre o poder presidencial quando seu partido não detém a presidência, mas não fazem nada para reduzi-lo quando possuem a oportunidade.

Os Estados Unidos Estão se Encaminhando para uma Ditadura? Is America Heading Toward Dictatorship? 